\title{
Tobacco Consumption Patterns in Labourers of Ahmedabad
}

\author{
Mamta Arvindbhai Patel ${ }^{1}$, Dr. C. D. Bhavsar ${ }^{2}$ \\ ${ }^{1}$ Aroma College of Commerce, Usmanpura, Ahmedabad - 13, India \\ ${ }^{2}$ Department of Statistics, School of Sciences, Gujarat University, Ahmedabad -09, India
}

\begin{abstract}
Research Objective: To monitor and investigate consumption patterns of tobacco products in labourers of Ahmedabad. Methods and Measures: The sample of 422 labourers (age 15 to 64 years) was selected by self organized population based survey. An unweighted dataset is part of survey design and rates and ratios are estimated with 95\% C.I. For the evaluation of consumption of tobacco products, different socio-demographic characteristics of respondents were selected as covariates. For the data collection a pretested questionnaire was prepared in two languages English and Gujarati. Statistical Analysis: The whole statistical analysis of the collected data was carried out by means of SPSS 21.0 using descriptive statistics and logistic regression for selection of the risk factors. Conclusion: From the study results we can conclude that a majority of the respondents were habituated with smokeless tobacco use. Highest prevalence of smoking was found in young and less educated labourers. No significant effect of awareness of ill effects is found on prevalence of smoking in labour class. The age between 35 to 44 years in labourers are found to have highest prevalence rate of smokeless tobacco use. Very high prevalence rates found in study indicate urgent need of effective tobacco control programs for labourers to get rid of this deadly habit.
\end{abstract}

Keywords: Tobacco, Labourers, Logistic regression, Health awareness

\section{Introduction}

A worker who does unskilled physical work for earning wages is called labourer. Labour class belongs to lower economical class category. There is an established relation between economically lower classes and high prevalence of tobacco consumption. Tobacco is a triggered weapon which kills millions of its users. An occasional tobacco use was initiated for its nutrition mediated effects for survival and pleasure. Now it has became an evil with many faces by converting into tobacco abuse from tobacco use. At present tobacco consumption is a burning issue related to human health and development. If we talk about tobacco consumed by labourers, a poor socio demographic category, they are more likely to consume tobacco frequently for two main reasons of cheaper tobacco products and psychological relief from consequent pain of full day labour. Tobacco consumption in urban area of Gujarat is a partially neglected issue and needs and urgent attention. Labour class community is one of the highest tobacco consumers availing communities including largest number of female consumers. By keeping this fact in mind, we have conducted study in our city Ahmedabad with the following objectives,

1) To determine the prevalence of tobacco consumption in adult labourers who are residents of Ahmedabad and between the age of 15 to 64 years.

2) To identify risk factors of different types of tobacco consumption among labourers of Ahmedabad.

\section{Material, Methods and Data Collection}

Design of study: It was a self organized cross sectional population based survey which included 422 adult labourers between age of 15 to 64 years from Ahmedabad city.

Selection of subjects: To select the subjects or respondents from labour population of Ahmedabad city a technique of simple random sampling is used. In the procedure respondents were selected randomly by balancing the gender selection and subgroup probability proportional to population size.

Data collection: The face to face survey was conducted to collect required data using a predesigned and pretested questionnaire (prepared in local language Gujarati). It was given to selected subjects of age between 15 to 64 years who are labourers and residents of Ahmedabad city. An unbiased assistance was provided to those respondents who were unable to fill questionnaire at their own (e.g. illiterates, physically unable etc.). Non responses were excluded from the sample.

\section{Statistical Analysis}

The whole statistical analysis of the collected data was carried out by means of SPSS 21.0 using binary logistic regression.

\subsection{Binary logistic regression with multiple independent variables}

For m explanatory variables

$\operatorname{logit}(\mathrm{p}(\mathrm{Y}))=\alpha+\beta_{1} \mathrm{X}_{1}+\beta_{2} \mathrm{X}_{2}+\ldots \ldots \ldots \ldots+\beta_{\mathrm{m}} \mathrm{X}_{\mathrm{m}}$,

Where $\operatorname{logit}(\mathrm{p})=\ln \left(\frac{p}{1-p}\right)=\alpha+\beta_{1} \mathrm{X}_{1}+\beta_{2} \mathrm{X}_{2}+\ldots \ldots \ldots \ldots+\beta_{\mathrm{m}} \mathrm{X}_{\mathrm{m}}$ and the odds $=\frac{p}{1-p}$

Or as a direct specification alternate

$\mathrm{p}$ or $\pi(\mathrm{x})=\frac{\exp \left(\alpha+\beta_{1} \mathrm{X}_{1}+\beta_{2} \mathrm{X}_{2}+\cdots \ldots \ldots \ldots+\beta_{\mathrm{m}} \mathrm{X}_{\mathrm{m}}\right)}{1+\exp \left(\alpha+\beta_{1} \mathrm{X}_{1}+\beta_{2} \mathrm{X}_{2}+\cdots \ldots \ldots .+\beta_{\mathrm{m}} \mathrm{X}_{\mathrm{m}}\right)},(\pi(x)=$ $\mathrm{P}(\mathrm{Y} / \mathrm{X}=\mathrm{x}))$

Here parameter $\beta_{\mathrm{i}}=$ effect of covariate $\mathrm{x}_{\mathrm{i}}$ on the log odds that $Y$ assumes 1 , controlling other covariates $x_{j}$, for instance, $\exp \left(\beta_{\mathrm{i}}\right)$ is the multiplicative effect on the odds of a unit increase in covariate $x_{i}$, at fixed levels of other covariates $x_{j}$. 


\section{International Journal of Science and Research (IJSR) \\ ISSN (Online): 2319-7064 \\ Index Copernicus Value (2013): 6.14 | Impact Factor (2015): 6.391}

\subsection{Selection of the variables}

\subsubsection{Response variable}

The present study focuses on the phenomenon of tobacco consumption therefore it was considered as response variable with two categories consumer (code 1) and non consumer (code 0).

\subsubsection{Explanatory Variables}

The following is a detailed review of explanatory variables we believe which have an effect on responses.

\begin{tabular}{|c|c|c|c|c|c|}
\hline $\begin{array}{l}\text { Variable } \\
\text { name }\end{array}$ & Categories & code & Variable name & Categories & code \\
\hline \multirow[t]{2}{*}{ Gender } & Female & 1 & Level of Education & $\begin{array}{l}\text { Education of } 8 \text { or more years } \\
\text { (ED-1) }\end{array}$ & 1 \\
\hline & Male & 2 & & 1-7 years of education(ED-2) & 2 \\
\hline \multirow[t]{5}{*}{ Age } & $55-64(\mathrm{~A}-1)$ & 1 & & No education (ED-3) & 3 \\
\hline & $45-54(\mathrm{~A}-2)$ & 2 & $\begin{array}{c}\text { Awareness of ill effects of active } \\
\text { smoking (ASA) }\end{array}$ & Yes & 1 \\
\hline & $35-44(\mathrm{~A}-3)$ & 3 & & No & 0 \\
\hline & $25-34(\mathrm{~A}-4)$ & 4 & $\begin{array}{c}\text { Awareness of ill effects of passive } \\
\text { smoking (PSA) }\end{array}$ & Yes & 1 \\
\hline & $15-24(\mathrm{~A}-5)$ & 5 & & No & 0 \\
\hline \multirow[t]{4}{*}{ Cast } & $\begin{array}{l}\text { Other backward } \\
\text { Class(OBC) }\end{array}$ & 1 & $\begin{array}{c}\text { Awareness of ill effects of } \\
\text { consumption of smokeless } \\
\text { tobacco (SLA) }\end{array}$ & Yes & 1 \\
\hline & Schedule tribe(ST) & 2 & & No & 0 \\
\hline & Schedule cast(SC) & 3 & & & \\
\hline & General (OPEN) & 4 & & & \\
\hline
\end{tabular}

3.2.3 Verifications of assumptions and checking of explanatory variables:

There is no violation of any assumption of MLR (Multiple logistic regression). Our dependent variable is binary by nature. There is no multi-co-linearity between independent variables. There are no outliers, high leverage values or highly influential points. The procedure of different phases of recalculated model fitting includes checking of standard errors, statistical significance of parameter estimates and goodness of fit. Explanatory variables with unusual results are excluded as per the requirement of validation.

Table 1: Analysis of association between covariates and daily smoking in labourers of Ahmedabad (estimates of parameters according to the selected model)

\begin{tabular}{|c|c|c|c|c|c|c|}
\hline \multicolumn{2}{|c|}{ Demographic variables } & \multicolumn{2}{|c|}{ Proportion } & \multicolumn{3}{|c|}{ Adjusted Odds ratio } \\
\hline \multirow{2}{*}{ Variable name } & \multirow{2}{*}{ Categories } & \multirow{2}{*}{ \# } & \multirow{2}{*}{$\%$} & \multirow{2}{*}{ O.R. } & \multicolumn{2}{|c|}{$95 \%$ C.I. } \\
\hline & & & & & L.B. & U.B. \\
\hline \multirow[t]{2}{*}{ Gender } & Female & 12 & 6.7 & $0.063 *$ & 0.031 & 0.127 \\
\hline & Male & 110 & 45.1 & 1 & - & - \\
\hline \multirow[t]{5}{*}{ Age } & $55-64$ & 8 & 20 & $0.251 *$ & 0.086 & 0.730 \\
\hline & $45-54$ & 32 & 32.7 & $0.296 *$ & 0.142 & 0.698 \\
\hline & $35-44$ & 18 & 16.4 & $0.101 *$ & 0.045 & 0.225 \\
\hline & $25-34$ & 21 & 25.6 & $0.309 *$ & 0.136 & 0.702 \\
\hline & $15-24$ & 43 & 46.7 & 1 & - & - \\
\hline \multirow[t]{4}{*}{ Cast } & OBC & 29 & 28.4 & 1.548 & 0.735 & 3.260 \\
\hline & ST & 19 & 32.8 & 2.350 & 0.968 & 5.704 \\
\hline & SC & 44 & 26.2 & 1.056 & 0.530 & 2.104 \\
\hline & General & 30 & 31.9 & 1 & - & - \\
\hline \multirow[t]{3}{*}{ Level of Education } & ED-1 & 4 & 28.6 & 0.589 & 0.114 & 3.05 \\
\hline & ED-2 & 41 & 33.6 & 0.882 & 0.457 & 1.704 \\
\hline & ED-3 & 77 & 28.1 & 1 & - & - \\
\hline \multirow[t]{2}{*}{ ASA } & $\mathrm{NO}$ & 27 & 22.9 & 1.094 & 0.567 & 2.110 \\
\hline & YES & 95 & 31.3 & 1 & - & - \\
\hline \multirow[t]{2}{*}{ PSA } & $\mathrm{NO}$ & 104 & 28.1 & 0.586 & 0.239 & 1.437 \\
\hline & YES & 18 & 34.6 & 1 & - & - \\
\hline \multirow[t]{2}{*}{ SLA } & $\mathrm{NO}$ & 75 & 26.8 & 0.890 & 0.467 & 1.718 \\
\hline & YES & 47 & 33.1 & 1 & - & - \\
\hline
\end{tabular}




\section{International Journal of Science and Research (IJSR) ISSN (Online): 2319-7064 \\ Index Copernicus Value (2013): 6.14 | Impact Factor (2015): 6.391}

Table 2: Analysis of association between covariates and daily use of smokeless tobacco in labourers of Ahmedabad (estimates of parameters according to the selected model)

\begin{tabular}{|c|c|c|c|c|c|c|}
\hline \multicolumn{2}{|c|}{ Demographic variables } & \multicolumn{2}{|c|}{ Proportion } & \multicolumn{3}{|c|}{ Adjusted Odds ratio } \\
\hline \multirow{2}{*}{ Variable name } & \multirow{2}{*}{ Categories } & \multirow{2}{*}{$\#$} & \multirow{2}{*}{$\%$} & \multirow{2}{*}{ O.R. } & \multicolumn{2}{|c|}{$95 \%$ C.I. } \\
\hline & & & & & L.B. & U.B. \\
\hline \multirow[t]{2}{*}{ Gender } & Female & 135 & 75.8 & $1.652 *$ & 1.034 & 2.639 \\
\hline & Male & 162 & 66.4 & 1 & - & - \\
\hline & & & & & & \\
\hline \multirow[t]{5}{*}{ Age } & $55-64$ & 28 & 70 & 0.930 & 0.385 & 2.244 \\
\hline & $45-54$ & 62 & 63.3 & 0.819 & 0.427 & 1.570 \\
\hline & $35-44$ & 90 & 81.8 & 0.971 & 0.989 & 3.932 \\
\hline & $25-34$ & 52 & 63.4 & 0.673 & 0.342 & 1.328 \\
\hline & $15-24$ & 65 & 70.7 & 1 & - & - \\
\hline & & & & & & \\
\hline \multirow[t]{4}{*}{ Cast } & OBC & 76 & 74.5 & 1.804 & 0.945 & 3.443 \\
\hline & ST & 35 & 60.3 & 0.956 & 0.462 & 1.979 \\
\hline & SC & 128 & 76.2 & 1.996 & 1.114 & 3.575 \\
\hline & General & 58 & 61.7 & 1 & - & - \\
\hline & & & & & & \\
\hline \multirow[t]{3}{*}{ Level of Education } & ED-1 & 10 & 71.4 & 1.468 & 0.367 & 5.874 \\
\hline & ED-2 & 95 & 70.9 & 1.101 & 0.625 & 1.938 \\
\hline & ED-3 & 192 & 70.1 & 1 & - & - \\
\hline \multirow[t]{2}{*}{ ASA } & $\mathrm{NO}$ & 86 & 72.9 & 1.042 & 0.603 & 1.803 \\
\hline & YES & 24 & 69.4 & 1 & - & - \\
\hline \multirow{2}{*}{ PSA } & NO & 259 & 70 & 0846 & 0383 & 1867 \\
\hline & YES & 38 & 73.1 & 1 & - & - \\
\hline \multirow[t]{2}{*}{ SLA } & NO & 198 & 70.7 & 1.087 & 0.616 & 1.918 \\
\hline & YES & 99 & 69.7 & 1 & - & - \\
\hline & = Upper & $\begin{array}{l}\text { O.R., } \\
\text { A, L.P }\end{array}$ & $\begin{array}{l}05 \text { anc } \\
\text { ver bo }\end{array}$ & $\begin{array}{l}\text { Odds ra } \\
=\text { Con }\end{array}$ & terval & \\
\hline
\end{tabular}

\section{Discussion}

Present study is a statistical study of tobacco consumption in any form of labourers (respondents) as effects of different socio-demographic predictors including awareness of ill effects of consumption of tobacco. According to the visible proportions of tobacco consumption of subjects, high prevalence of smoking is frequent in male subjects than female. Female subjects have general tendency of smokeless tobacco consumption. In young and middle aged (between 45 to 54) labourers smoking is highly prevalent. Similar patterns of smoking are found in all cast. Smokeless tobacco products have more prevalent use in female labourers. Uses of smokeless tobacco products in lower cast are comparatively high. But these study results may not clear the picture of combined effects of set of predictors as they are individual proportions. To overcome this problem an advance statistical analysis is needed.

Like all other regressions, multiple logistic regression is also a predictive analysis. Logistic regression is used to predict membership of categories of response variable. It can be considered as a zoomed profile of simple proportionate values of tobacco use in any form according to their sociodemographic characteristics and awareness of ill effects. Table 1 and 2 presents estimated odds ratios for use of combusting (smoking) and non combusting (smokeless) tobacco products respectively using MLR model. It can be seen that some of the categories of predictors are not statistically significant (without*). Odds ratios or $\exp (\mathrm{b})$ of the independent variables are predicted changes in odds for the unit increase in respective dependent variable. The values greater than 1 , less than 1 and equal to 1 of odds ratio represent corresponding increase, decrease and no effect on response variable respectively.

\section{Results}

Table 1 summarizes proportions and the output of procedure of multiple logistic regression of use of combusting tobacco products among labourers of Ahmedabad. Female labourers are comparatively less likely $\left(\mathrm{OR}=0.063^{*}<1\right)$ to get addicted by smoking than male labourers. Labourers of age 25 years or more are significantly less likely (ORs $-0.251^{*}$, $0.296 *, 0.101 *, 0.309^{*}$ all $<1$ ) to become daily smokers than young labourers between age of 15 to 24 years. Due to similar patterns in cast, education and awareness they have no significant adjusted effect on smoking status of labourers.

Predicting response probabilities:

Log odds $(\mathrm{p})=\mathrm{T}=\alpha+\beta_{1} \mathrm{X}_{1}+\beta_{2} \mathrm{X}_{2}+\ldots \ldots \ldots \ldots+\beta_{\mathrm{m}} \mathrm{X}_{\mathrm{m}}$

Log odds $(\mathrm{p})=1.383-2.765$ (FEMALE) $-1.383(\mathrm{~A}-1)-$

$1.216(\mathrm{~A}-2)-2.291(\mathrm{~A}-3)-1.173(\mathrm{~A}-4)+$

$0.437(\mathrm{OBC})+0.854(\mathrm{ST})+0.055(\mathrm{SC})-0.529(\mathrm{ED}-1)-$

$0.126(\mathrm{ED}-2)+$

0.090(ASA-NO) - 0.535(PSA-NO) - 0.116(SLA-NO)

Now Odds $(\mathrm{p})=\exp (\log$ odds $(\mathrm{p}))$

And predicted probability $(\mathrm{p})=\frac{\text { Odds }(p)}{1+\text { Odds }(p)}$ 


\section{International Journal of Science and Research (IJSR) \\ ISSN (Online): 2319-7064 \\ Index Copernicus Value (2013): 6.14 | Impact Factor (2015): 6.391}

For an example, let a case of predicting probability of getting an exposure of smoking of a labourer with following details :

\begin{tabular}{|c|c|c|c|c|c|c|}
\hline Gender & Age & Cast & Education & ASA & PSA & SLA \\
\hline male & 47 years & SC & 1 to 7 year & Yes & No & No \\
\hline
\end{tabular}

Log odds $=1.383+1(0)-1.216(1)+0.055(1)-0.126(1)+$ $1(0)-0.535(1)-0.116(1)=-0.555$

Odds $=\exp (-0.555)=0.574$

Predicted Probability $=0.574 / 1+0.574=0.36$

This value 0.36 is the probability of the considered case get addicted by smoking.

Table 2 summarizes proportions and the output of procedure of multiple logistic regression of use of non combusting tobacco products among labourers of Ahmedabad. Female labourers are comparatively more likely $(\mathrm{OR}=1.652 *>1)$ to get addicted by smoking than male labourers. Due to similar patterns age, cast, education and awareness they have no significant adjusted effect on smoking status of labourers. Predicting response probabilities:

Log odds $(p)=T=\alpha+\beta_{1} X_{1}+\beta_{2} X_{2}+\ldots \ldots \ldots . .+\beta_{m} X_{m}$

Log odds $(\mathrm{p})=0.298+0.502$ (FEMALE) $-0.073(\mathrm{~A}-1)-0.2$

$(\mathrm{A}-2)+0.679(\mathrm{~A}-3)-0.395(\mathrm{~A}-4)+$

$0.590(\mathrm{OBC})-0.044(\mathrm{ST})+0.691(\mathrm{SC})+0.384(\mathrm{ED}-1)+$ $0.096(\mathrm{ED}-2)+$

$0.41($ ASA-NO) $-0.167(\mathrm{PSA}-\mathrm{NO})+0.084(\mathrm{SLA}-\mathrm{NO})$

Now Odds $(\mathrm{p})=\exp (\log$ odds $(\mathrm{p}))$

And predicted probability $(\mathrm{p})=\frac{\text { Odds }(p)}{1+\operatorname{Odds}(p)}$

For an example, let a case of predicting probability of getting an exposure of daily smokeless tobacco use of a labourer with following details:

\begin{tabular}{|c|c|c|c|c|c|c|}
\hline Gender & Age & Cast & Education & ASA & PSA & SLA \\
\hline female & 37 years & SC & No education & No & No & No \\
\hline
\end{tabular}

Log odds $=0.298+0.502(1)+0.679(1)+0.691(1)+1(0)+$ $0.41(1)-0.167(1)+0.084(1)=2.497$

Odds $=\exp (2.497)=12.146$

Predicted Probability $=12.146 / 1+12.146=0.92$

This value 0.92 is the probability of the considered case get addicted by smokeless tobacco use.

\section{Conclusion}

From the study results we can conclude that a majority of the respondents were habituated with smokeless tobacco use. Highest prevalence of smoking was found in young and less educated labourers. No significant effect of awareness of ill effects is found on prevalence of smoking. The age between 35 to 44 years in labourers are found to have highest prevalence rate of smokeless tobacco use. Very high prevalence rates found in study indicate urgent need of effective tobacco control programs for labourers to get rid of this deadly habit.

\section{References}

[1] Sekhon H, Minhas S (2014): A study of tobacco use amongst migrant labourers in North India, International
Journal of Innovative Research and Development, 3(4): 109-113.

[2] Hosmer D W, Lemeshow S (2000): Applied logistic regression. US, Wiley-Inter science.

[3] Tabachnick B G, Fidell L S, Osterlind S J (2001): Using multivariate statistics. US, Allyn and Bacon Boston.

[4] Bailey S L (1992): Adolescents' multi substance use patterns: the role of heavy alcohol and cigarette use, American Journal of Public Health , September :9(82): 1220- 1224.

[5] Garg K N, Raj V, Chandra S (2013): Trends in frequency and duration of tobacco habit in relation to potentially malignant lesion: A 3 years retrospective study, Journal of Oral and Maxillofacial Pathology, JOMFP:17(2): 201206.

[6] Gupta S, Sarpal S S, Kumar D, Kaur T, Arora S (2013): Prevalence, pattern and familial effects of substance use among the male college students-A North Indian Study, Journal of Clinical and Diagnostic Research, 7(8): 16321636.

[7] Narain R, Sardana S, Gupta S, Sehgal A (2011): Age at initiation and prevalence of tobacco use among school children in Noida: A cross-sectional questionnaire based survey, The Indian Journal of Medical Research, 133(3): 300.

[8] Gilani S I, Leon D A (2013): Prevalence and sociodemographic determinants of tobacco use among adults in Pakistan: findings of a nationwide survey conducted in 2012, Population Health Metrics, 11 (1): 1.

[9] Lemeshow S, Hosmer D W (1982): A review of goodness of fit statistics for use in the development of logistic regression models, American Journal of Epidemioloy, 115(1): 92-106. 